\title{
Management of IgA vasculitis nephritis (Henoch- Schonlein purpura nephritis) in Children
}

\author{
Meekyng Namgoong, M.D., Ph.D. \\ Department of Pediatrics, Wonju \\ Severance Christian Hospital, Yonsei \\ University Wonju College of Medicine, \\ Wonju, Korea
}

Corresponding author:

Meekyung Namgoong,.M.D., Ph.D.

Department of Pediatrics, Wonju

Severance Christian Hospital, Ilsan-ro 20,

Wonju, 26426, Korea

Tel: $+82-33-741-1282$

Fax: +82-33-732-6229

E-mail:ngmk@yonsei.ac.kr

Received: 19 March 2020

Revised: 30 March 2020

Accepted: 4 April 2020
Immunoglobulin (Ig)A vasculitis nephritis (IgAVN), also referred to as HenochSchönlein purpura nephritis, is a relatively benign disease in children. However, two 24-year European cohort studies have reported high sustained rates of hypertension, severe proteinuria, and renal dysfunction in patients with IgAVN. Notably, the incidence and exacerbation rates of proteinuria, hypertension, and renal dysfunction during pregnancy were high even in women who recovered from IgAVN before pregnancy. Patients with IgAVN need lifelong care. Trials have been performed to investigate early biomarkers and genes associated with poor prognosis to identify high-risk patients in whom IgAVN may progress to severe renal disease. Urinary $\lg \mathrm{A} / \mathrm{cr}$, IgM/cr levels, and $H L A B 35$ and angiotensinogen gene expression were shown to be predictors of progression of IgAVN to severe renal dysfunction. The 2019 Single Hub and Access point for paediatric Rheumatology in Europe (SHARE) initiative group published guidelines for pediatric IgAVN, following the Kidney Disease: Improving Global Outcomes (KDIGO) guidelines established in 2012. Compared with the KDIGO guidelines, the SHARE guidelines recommend earlier corticosteroid administration in cases of mild proteinuria $(>0.5 \mathrm{~g} / \mathrm{d}$ ). Clinical trials of targeted budesonide delivery to the distal ileum, monoclonal antibody targeting C5, eculizumab and anti-CD20 monoclonal antibody administration, among others are currently underway in patients with IgA nephropathy. It is expected that newer therapeutic agents would become available for IgAVN in the near future. This review summarizes IgAVN with emphasis on recently published literature, including possible preventive strategies, predictive biomarkers for progression of IgAVN, and various treatments.

Key words: IgA vasculitis nephritis, Management, Prognosis, Henoch-Schönlein purpura nephritis

\section{Introduction}

Renal impairment is a major complication of immunoglobulin A vasculitis (IgAV), and renal manifestations of IgAV are variable. IgA vasculitis nephritis $(\mathrm{IgAVN})$ is a relatively benign disease in children ${ }^{1)}$. However, long-term cohort studies have shown high sustained rates of severe proteinuria and renal dysfunction in these patients during adulthood, and patients with a history of IgAVN in childhood may experience a poor quality of life. Patients with IgAVN need lifelong care and observation. Trials have been performed to investigate early biomarkers and genes associated with poor prognosis to

\footnotetext{
This is an open-access article distributed under the terms of the Creative Commons Attribution Non-Commercial License (http:// which permits unrestricted non-commercia use, distribution, and reproduction in an medium, provided the original work is properly cited.
}

Pediatric Nephrology 
identify high-risk patients in whom IgAVN can progress to severe renal dysfunction and to establish an optimal treatment.

This systematic review of the recently published literature focused on the following questions:

a. Can biomarkers and genes predict renal involvement in IgAV?

b. If specific markers can identify high-risk patients in whom IgAVN can progress to severe renal dysfunction, can these predictors be used to prevent progression of renal disease?

c. Are there any new recommendations for IgAVN management?

\section{Nomenclature used for immunoglobulin A vasculitis/Henoch-Schönlein purpura}

The International Chapel Hill Consensus Conference (CHCC 2012) revised the nomenclature for vasculitis to include the pathophysiology of vasculitis in its name. Henoch-Schönlein purpura (HSP) is associated with IgA1dominant immune deposits in small blood vessels (predominantly capillaries, venules, or arterioles). Therefore, the CHCC 2012 replaced the eponym "Henoch-Schönlein purpura" with IgA vasculitis to better define the pathophysiological features observed in this condition ${ }^{2)}$. In this review, IgAVN has been used to replace the eponym Henoch-Schönlein purpura nephritis.

\section{Diagnosis of immunoglobulin A vasculitis}

In 1990, the American College of Rheumatology (ACR) proposed criteria to distinguish HSP (IgAV) from other vasculitides. Based on the ACR recommendations, the diagnostic criteria for HSP (sensitivity $87.1 \%$, specificity $87.7 \%$ ) include at least two of the following features: (1) age $\leq 20$ years at disease onset, (2) palpable purpura, (3) acute abdominal pain, and (4) biopsy showing granulocytes in the walls of small arterioles/venules ${ }^{3)}$.

In 2010, the European League against Rheumatism and the Paediatric Rheumatology European Society (EULAR/ PReS) jointly validated the criteria for HSP (IgAV) previ- ously proposed by the ACR. These bodies suggested that IgAV should be diagnosed based on purpura or erythema (required criterion) predominantly observed over the lower extremities plus identification of one of these four features: (1) diffuse abdominal pain, (2) histopathological findings of typical leukocytoclastic vasculitis (LCV) with predominant IgA deposits or proliferative glomerulonephritis with predominant IgA deposits, (3) arthritis or arthralgia and, (4) renal involvement (proteinuria $>0.3 \mathrm{~g} / 24$ hours or $>30$ $\mathrm{mmol} / \mathrm{mg}$ of urine albumin to creatinine ratio in a spot urine morning sample, and/or hematuria : $>5$ red blood cells/high-power field or $\geq 2+$ on dipstick or red blood cell casts in the urinary sediment $)^{4)}$.

Compared with the ACR criteria, the EULAR/Paediatric Rheumatology International Trials Organisation (PRINTO)/ PReS criteria focus on histopathological features of typical LCV with predominant IgA deposits or proliferative glomerulonephritis with predominant IgA deposits as useful criteria in all suspected cases with atypical distribution of purpura, and joint and renal involvement. Notably, the EULAR/PRINTO/PReS criteria showed better sensitivity and specificity than the ACR criteria ${ }^{4)}$.

\section{Renal involvement in patients with immuno- globulin A vasculitis}

Renal involvement occurs in $20-50 \%$ of patients with $\operatorname{IgAV}^{5,6)}$. Microscopic hematuria is the most common finding, and $25 \%$ of patients with IgAVN also show gross hematuria. Proteinuria occurs in $70 \%$ and isolated proteinuria in $9 \%$ of patients with IgAVN. Nephritis rarely precedes purpura onset, and nearly $97 \%$ of patients with nephritis develop urinary abnormalities within 6 months after the onset of other symptoms. Therefore, weekly urinalysis is warranted during the active phase of IgAV, followed by urinalysis performed each month for 6 months thereafter. Evidence of nephritis necessitates minimum 24-month follow-up despite resolution of urinary abnormalities ${ }^{5-10)}$. 
Risk factors associated with renal involvement in patients with immunoglobulin A vasculitis

\section{Clinical risk factors}

Persistent purpura and gastrointestinal bleeding, particularly when associated with severe abdominal pain are known predictors of nephritis ${ }^{11}$. A study has reported that patients with purpura recurrence showed a higher risk of renal involvement than those with monocyclic disease ${ }^{12}$.

\section{Genes and biomarkers}

The human leukocyte antigen (HLA) gene complex and other genes associated with immunity and inflammation are known etiopathogenetic contributors to renal involvement in IgAV.

1) Genes associated with galactosylation of immunoglobulin A1

Aberrant galactosylation of $\operatorname{Ig} A 1$ contributes to $\operatorname{IgAV}^{13)}$. Reduced activity of the C1GALT1 (Gene ID: 56913) gene encoding core $1 \beta 1$,3-galactosyl transferase can cause aberrant glycosylation of $\operatorname{IgA} 1^{14)}$. He et al. ${ }^{15)}$ reported that 1365 G/A allele frequency of the C1GALT1 gene was associated with increased susceptibility to $\operatorname{IgAVN}(P=0.0008$, adjusted $\left.P^{\prime}=0.004\right)$ with an odds ratio $1.716,95 \%$ confidence interval 1.151-2.560.

\section{2) Nitric oxide synthase polymorphisms}

Reportedly, cytokine-mediated-neutrophil-dependent injury to endothelial cells plays a key role in the pathogenesis of IgAV and may promote nitric oxide (NO) production ${ }^{16)}$. Jiang et al. ${ }^{17)}$ investigated the potential association between nitric oxide synthase (iNOS) polymorphisms and the risk of progression of IgAV to IgAVN in a Chinese Han population. Children with IgAVN showed a significantly higher frequency of (CCTTT)12 repeats and A allele of rs2297518 than those with IgAV without nephritis.

\section{3) Other biomarkers}

The angiotensin-converting enzyme $(A C E)$ gene ${ }^{18)}$, which is associated with vasomotor and endothelial function, the interleukin $(I L) 8$ gene $^{19)}$, which is associated with anti-inflammatory action, and the HLA-B35 (HLAb35) gene (reported by studies from Spain and the $\mathrm{UK}^{20,21)}$ were shown to be associated with IgAVN. Patients with HLA-B35 may be genetically more susceptible to recurrent episodes of IgAVN, precipitated by a heterogeneous group of infective stimuli resulting in a protracted illness with significant renal involvement. Reportedly, the ACE DD genotype or $\mathrm{D}$ allele is associated with IgAVN susceptibility in Asians ${ }^{22}$.

\section{Proteomic analysis}

In 2015, He et al. ${ }^{23)}$ performed a comparative analysis of serum proteomes in $\operatorname{IgAV}(\mathrm{n}=6), \operatorname{IgAVN}(\mathrm{n}=6)$, and controls ( $\mathrm{n}=7$ ) and identified a few differentially abundant proteins, such as $\mathrm{C} 4 \mathrm{a}$, serum amyloid $\mathrm{A}$, angiotensinogen, and kininogen 1 in patients with IgAV and IgAVN. They specifically observed that angiotensinogen concentration was positively associated with IgAVN and could serve as a potential biomarker for progression of IgAV.

\section{Prevention of renal involvement in patients with immunoglobulin $A$ vasculitis}

Recent studies have failed to prove the efficacy of early glucocorticoid administration to avoid renal injury in these patients. No trial identified in updated literature reviews supports the use of drugs to prevent nephritis in all children with $\operatorname{Ig} A V^{24-27)}$.

\section{Long-term prognosis of immunoglobulin A vasculitis nephritis}

The prognosis of IgAVN is better in children than in adults. A multicenter collaborative Italian study that included a mean 5-year follow-up reported that the risk of end-stage kidney disease (ESKD) was higher in adults than in children $(15.8 \% \text { vs. } 7 \%)^{1,28)}$. However, long-term prognosis in children with long life expectancy may yield different answers. The available literature describes 2 cohort studies that have included long-term follow-up ( $>20$ years). A study in the UK investigated children with IgAVN who were treated in the early 70 s and were followed-up until 1992 (median follow-up of 23.4 years) ${ }^{29}$. Notably, $82 \%$ of patients recovered among those with mild hematuria and proteinuria, and $44 \%$ showed persistent hypertension or 
kidney damage among those with nephritic and nephrotic syndrome; $18 \%$ of patients with early mild kidney disease showed persistent urinary abnormalities and 7.7\% had ESKD. The overall ESKD incidence was $38.5 \%$ of all patients with IgAVN. Notably, severe clinical symptoms and significant renal biopsy findings were strongly associated with poor long-term prognosis. Regardless of the initial clinical symptoms, complications such as proteinuria and hypertension occurred in 16 of 44 pregnancies. A 24-year longterm cohort study in Finland investigated children with IgAVN treated between the $60 \mathrm{~s}$ and $80 \mathrm{~s}^{30)}$ and reported that $35 \%$ of patients with early severe renal symptoms showed persistent severe abnormalities. Mild urinary abnormalities persisted in $28 \%$ of children with mild renal symptoms and severe abnormalities in $11 \%$. Overall, ESKD occurred in $10 \%$ of patients. The relative risk for poor renal outcomes was 5.0 in females and 2.0 in males. Initial renal biopsy findings were not associated with the risk of a poor renal outcome. Pregnancies were complicated by hypertension and/or proteinuria in $70 \%$ of women, and $56 \%$ of women with complicated pregnancies showed poor renal outcomes.

The aforementioned cohort studies indicated that pediatric IgAVN is no longer considered a mild disease. Proteinuria and hematuria may be associated with a $15 \%$ risk and a combination of nephritic-nephrotic syndrome may be associated with a $50 \%$ risk of progression to ESKD. These long-term studies highlight the importance of long-term follow-up in all patients during adulthood. Notably, all women with a history of IgAVN require close observation during and after pregnancy.

Prevention of progression to severe kidney disease and renal sequelae in patients with immunoglobulin A vasculitis nephritis

\section{Can early treatment with corticosteroids or cytotoxic agents prevent progression of immunoglobulin A vasculitis nephritis to severe kidney disease?}

The Kidney Disease: Improving Global Outcomes (KDIGO) group systematically reviewed the available literature $^{27)}$ and reported that compared with no therapy or supportive therapy, early treatment with corticosteroids
(CS) did not significantly contribute or contributed only minimally to severe kidney disease (nephrotic-range proteinuria, hypertension, or reduced kidney function). A long-term (20-year median follow-up) study in the USA reported that among patients who underwent a renal biopsy, $66 \%$ showed normal renal function and normal urinalysis, and $21 \%$ of patients progressed to ESKD. Cytotoxic agents served as the sole contributor to ESKD. However, this report did not describe any significant initial features that could help to identify children at risk of disease progression $^{31)}$.

\section{Can early aggressive treatment prevent} exacerbation of renal disease based on identification of glomerular crescent deposition as predictors of renal sequelae?

A study investigating adults with IgAVN reported that greater crescent deposition was associated with more severe renal manifestations and a poorer treatment response; however, whether the percentage of crescent deposits is associated with a higher risk of late renal insufficiency remains controversia ${ }^{32,33)}$. Multivariate analysis performed in a study by Pillebout et al. ${ }^{34)}$ showed that renal dysfunction and proteinuria at presentation, renal biopsy findings, the degree of interstitial fibrosis, percentage of sclerotic glomeruli, and glomerular fibrinoid necrosis were associated with poor renal prognosis. The percentage of crescent deposits is used as a criterion for severe nephritis warranting aggressive treatment in patients with IgAVN. The Cochrane collaboration concluded that there is a lack of evidence to support immunosuppressant administration in patients without severe nephritis considering that only a few poor quality trials have reported their use ${ }^{27)}$. Niaudet et al. ${ }^{35)}$ suggested that early treatment might prevent progression of cellular crescent deposition to fibrosis and consequent chronic kidney disease. Plasmapheresis effectively removes IgA-containing complexes and prevents the development of and aids in resolution of crescents ${ }^{36,37}$. Further clinical trials are required to investigate more specific treatments to prevent monocyte influx into the Bowman's space. Selective blockade of IL-1 with IL-1 receptor antagonists and of tumor necrosis factor (TNF) with soluble TNF receptors markedly reduces crescent formation by reducing the expression of adhesion molecules and the recruitment of 
macrophages in experimental models of glomerulonephritis $^{38,39)}$.

\section{Can blood and urinary biomarkers, or genes} detect the early signs of progression of immunoglobulin A vasculitis nephritis to severe renal dysfunction?

Institution of treatment only after renal biopsy leads to delayed management. Therefore, establishing less invasive and user-friendly laboratory tests are essential. Studies have investigated the role of genes, as well as blood and urinary biomarkers as predictors of progression of IgAVN to severe renal dysfunction.

1) Blood and urinary biomarkers

A French national cohort study $(2017)^{1)}$ investigated blood and urinary biomarkers at the onset of skin rash and observed that children with IgAV with renal involvement at the time of diagnosis presented with serum galactose deficient (Gd)-IgA1 and urinary IgA, IgG, IgM, IL-6, IL-8, IL-10, and IgA-IgG and IgA-sCD89 complexes. Specifically, urinary $\operatorname{Ig} \mathrm{A} / \mathrm{cr}$ and $\operatorname{IgM} / \mathrm{cr}$ were significantly associated with IgAVN. Therefore, it is reasonable to conclude that patients showing these biomarkers are predisposed to subsequent renal dysfunction. However, a limitation of the study cannot be ignored; although 22 of the 33 patients (66.3\%) showed severe disease with urinary protein creatinine ratio $>1.0$, the authors did not observe an association between histopathological findings and the aforementioned biomarkers.

2) Non-human leukocyte antigen region inflammatory and anti-inflammatory genes and vasomotor and endothelial function regulation genes

Studies have investigated the role of genes involved in autoimmune or vascular inflammatory pathways. A systematic review reported by Raquel et al.(2017) ${ }^{40)}$ reported that transforming growth factor beta 1, IL8, C-C Motif Chemokine Ligand 5, selectin $\mathrm{P}$, angiotensin, $A C E$, paired box 2 , endothelial NOS, vascular endothelial growth factor, and the Mediterranean fever gene were associated with vasculitis severity. Therefore, these parameters are useful indicators of renal injury and/or renal sequelae markers.
3) Long non-coding RNA

Long non-coding RNA (lncRNA) (characterized by $>200$ nucleotides and lacking coding potential) regulate coding genes on the level of $>90 \%$ of all transcription and posttranscription ${ }^{41,42}$. They modulate small RNA and protein function and epigenetic modifications and serve as enhancer RNA. They display a highly tissue-specific pattern of expression and participate in several processes involved with development, health and disease. Pang et al. ${ }^{43)}$ reported that lncRNA were associated with the $\mathrm{p} 53$ signaling pathway and apoptosis-associated genes ( $A K T 2$ and FAS), as well as tumor protein 53 , phosphatase and tensin homolog in patients with IgAVN. If further studies can conclusively prove the role of lncRNA in apoptosis, lncRNAs may be useful therapeutic targets in humans.

\section{Treatment of immunoglobulin A vasculitis nephritis}

The therapeutic recommendations for pediatric IgAVN currently followed in clinical practice are based on the KDIGO 2012 and SHARE 2019 guidelines. These guidelines are based on the recommendations of an expert panel and are not evidence based.

\section{2012 Kidney Disease: Improving Global Outcomes guidelines}

These recommendations were similar to those established for the management of IgA nephropathy (IgAN) and suggest that the therapeutic protocol used to treat IgAVN in children should be similar to that used in adults ${ }^{44)}$. However, the pathophysiological findings in IgAN differ from those in IgAVN. IgAVN in children tends to rapidly progress to a severe form and crescent deposition is more common in children than in adults with IgAVN ${ }^{45,46}$. Additionally, long-term follow-up in patients has shown that compared to the extent of crescent deposition, histopathological findings indicating chronic renal disease were more relevant as predictors of renal prognosis ${ }^{33,34)}$ (Table 1).

These guidelines recommend the 3-6 month administration of $A C E$ inhibitors (ACEi) or angiotensin receptor blockers (ARBs) in children with proteinuria $>0.5 \mathrm{~g} /$ day (including those with nephrotic syndrome) and glucocorti- 
coid therapy is necessary in patients refractory to this treatment. Pediatric nephrologists are concerned that delaying the use of potentially effective therapy, such as methylprednisolone (MP) could predispose children to chronic renal disease in the long term ${ }^{35,47,48)}$.

\section{2018 Kidney Disease: Improving Global Outcomes} glomerulonephritis guidelines update - Evidence summary in patients with immunoglobulin $A$ nephropathy and immunoglobulin $A$ vasculitis nephritis ${ }^{49}$

These guidelines were established in 2018 and state that compared to no therapy or supportive therapy, early treatment with CS contributed minimally or did not contribute at all to persistent kidney disease at 6 and 12 months and severe kidney disease in adults. Additionally, these guidelines state that the efficacy of cyclophosphamide (CYC) alone or mycophenolate mofetil (MMF) and azathioprine (AZA) is unclear in patients with severe kidney disease ${ }^{49,50)}$ (Table 2).

\section{2019 Kidney Disease: Improving Global Outcomes conference report}

The KDIGO initiative organized a Controversies Conference on glomerular diseases in November 2017, which reviewed the role of steroids and immunosuppressive therapy in patients with IgAN but not IgA vasculitis ${ }^{51,52)}$. The KDIGO guidelines suggest that CS (but not CYC/AZA) may reduce proteinuria, although the effect on renal function remains

Table 1. 2012 Kidney Disease: Improving Global Outcomes Treatment Guidelines for Henoch-Schönlein Purpura Nephritis in Children

11.1: Treatment of HSP nephritis in children

11.1.1: We suggest that children with HSP nephritis and persistent proteinuria, $>0.5-1 \mathrm{~g} / \mathrm{d}$ per $1.73 \mathrm{~m}^{2}$, are treated with ACE-I or ARBs. (2D)

11.1.2: We suggest that children with persistent proteinuria, $>1 \mathrm{~g} / \mathrm{d}$ per $1.73 \mathrm{~m}^{2}$, after a trial of angiotensin converting enzyme inhibitor(ACE-l) or angiotensin receptor blockers(ARBs), and GFR $>50 \mathrm{ml} / \mathrm{min}$ per $1.73 \mathrm{~m}^{2}$, be treated the same as for IgA nephritis (IgAN) with a 6-month course of corticosteroid therapy (see Chapter 10). (2D)

11.2: Treatment of crescentic HSP nephritis in children

11.2.1: We suggest that children with crescentic HSP with nephrotic syndrome and/or deteriorating kidney function are treated the same as for crescentic IgAN (see Recommendation 10.6.3). (2D)

10.6.3.1: Define crescentic IgAN as IgAN with crescents in more than $50 \%$ of glomeruli in the renal biopsy with rapidly progressive renal deterioration (Not Graded)

10.6.3.2: We suggest the use of steroids and cyclophosphamide in patients with IgAN and rapidly progressive crescentic IgAN, analogous to the treatment of ANCA vasculitis (see Chapter 13). (2D). controversial $^{53)}$.

\subsection{European consensus-based} recommendations for diagnosis and treatment of immunoglobulin A vasculitis-The SHARE initiative recommendation

At the most recent SHARE consortium in 2018, based on consensus, 16 pediatric rheumatologists, nephrologists, and pathologists from seven countries developed recommendations for the diagnosis and treatment of IgAVN in children $^{54)}$ (Fig. 1). Definitions to grade the severity of IgAVN and proteinuria are shown in Table 3. Recommendations for diagnosis of IgAVN are shown in Table 4. Similar to

Table 2. 2018 Kidney Disease: Improving Global Outcomes Glomerulonephritis Guideline Update-Evidence Summary in Immunoglobulin A Nephropathy and Immunoglobulin A Vasculitis Nephritis

Preventing persistent kidney disease in patients newly diagnosed with HSP nephritis

-Corticosteroids versus placebo or supportive therapy

- No studies examined the critical and important outcomes (all-cause mortality, end-stage kidney disease, $\geq 50 \%$ GFR loss, infection, malignancy, complete remission, annual GFR loss).

- Compared to no supportive therapy, treatment with steroids probably has Little or no difference on the risk of development of kidney disease (RR $0.74,95 \% \mathrm{Cl} 0.42$ to $1.32 ; 5$ studies, 746 participants)

- Compared to no supportive therapy, treatment with steroids may have little or no difference on the persistence of continuing kidney disease at 6 (RR $0.51,95 \% \mathrm{Cl} 0.21$ to 1.11 ) and 12 months (RR $1.06,95 \% \mathrm{Cl} 0.38$ to 2.91), and the development of severe kidney disease (nephrotic range proteinuria, hypertension or reduced kidney function) (RR 1.58, 95\%Cl 0.42 to 6.0$)$.

Treating patients with HSP nephritis and severe kidney disease

-Cyclophosphamide versus supportive therapy

- Cyclophosphamide compared to supportive therapy may make little or no difference to the development of persistent kidney disease (RR 1.07, $95 \% \mathrm{Cl} 0.65$ to $1.78 ; 1$ study, 56 participants) or persistent severe kidney disease (with nephrotic range proteinuria, hypertension or reduced kidney function) (RR 0.88. 95\%Cl 0.37 to 2.09; 1 study, 56 participants). There was insufficient evidence for other critical or important outcomes. -Cyclophosphamide plus steroids versus steroids alone

- In one study (CESAR Study 2010), the addition of cyclophosphamide with steroids compared to steroids alone made no difference to all-cause mortality, end-stage kidney disease, infection, induction of diabetes and complete remission (disease activity (BVAS) $=0$ at 6 months) at 6 months. -Cyclosporine versus methylprednisolone

- This has been examined in one small RCT (Jahuloa 2010). Either critical or important outcomes were not reported in this RCT or due to the very low certainty of evidence (study limitations and very serious imprecision) the effects of treatment are unclear.

-Mycophenolate mofetil versus azathioprine

- This has been examined in one small RCT (Fuentes 2010). Either critical or important outcomes were not examined in this RCT or due to the very low certainty of evidence (study limitations and very serious imprecision) the effects of treatment are unclear.

-Mycophenolate mofetil versus leflunomide

- This has only been examined in one small RCT (Du 2016). Either critical or important outcomes were not examined in this RCT or due to the very low certainty of evidence (study limitations and very serious imprecision) the effects of treatment are unclear. 
KDIGO guidelines, the SHARE initiative recommends the administration of CS, AZA, MMF, and CYC; however, this group concluded that calcineurin inhibitors or oral CYC is ineffective in these patients. Compared to KDIGO recommendations, SHARE recommends earlier administration of ACEi and early initiation of oral CS even in mild cases of IgAVN (Protin creatinine ratio PCR $<100 \mathrm{mg} / \mathrm{mmol}=$ $0.88 \mathrm{mg} / \mathrm{mg}$ ). Oral prednisolone and/or pulsed MP is recommended as first-line treatment for moderate IgAVN

Table 3. Definitions of Severity of Immunoglobulin A Vasculitis Nephritis in SHARE Recommendations

\begin{tabular}{ll}
\hline Severity of IgAV nephritis & \multicolumn{1}{c}{ Definition } \\
\hline Mild & $\begin{array}{l}\text { Normal GFR* and mild }{ }^{\dagger} \text { or moderate } \\
\text { inuria }\end{array}$ \\
Moderate & $<50 \%$ crescents on renal biopsy and impaired \\
& GFR or severe persistent proteinuriae [44] \\
Severe & $>50 \%$ crescents on renal biopsy and impaired \\
& GFRc or severe persistent proteinuriae [44] \\
Persistent proteinuria & UP:UC ratio $>250 \mathrm{mg} / \mathrm{mmol}$ for 4 weeks \\
& UP:UC ratio $>100 \mathrm{mg} / \mathrm{mmol}$ for 3 months \\
& UP:UC ratio $>50 \mathrm{mg} / \mathrm{mmol}$ for 6 months \\
\hline
\end{tabular}

*Normal GFR: $>80 \mathrm{ml} / \mathrm{min} / 1.73 \mathrm{~m}^{2}$.

${ }^{\dagger}$ Mild proteinuria: UP:UC ratio $<100 \mathrm{mg} / \mathrm{mmol}$ (in an early morning urine sample).

${ }^{\ddagger}$ Moderate proteinuria: UP:UC ratio $100-250 \mathrm{mg} / \mathrm{mmol}$ (in an early morning urine sample).

Impaired GFR: $<80 \mathrm{ml} / \mathrm{min} / 1.73 \mathrm{~m}^{2}$.

"Severe persistent proteinuria: $>250 \mathrm{mg} / \mathrm{mmol}$ for at least 4 weeks.

Note: $1 \mathrm{~g} /$ day of proteinuria (in $24 \mathrm{~h}$ urine collection)=UP:UC (early morning UP:UC ratio) of $100 \mathrm{mg} / \mathrm{mmol}=U A: U C$ (early morning UA:UC ratio) of $70 \mathrm{mg} / \mathrm{mmol}$. This approximates to urine dipstick testing for proteinuria of $150 \mathrm{mg} / \mathrm{dL}$.

Abbreviations: UP:UC, urine protein:urine creatinine ratio; UP:UC, urine albumin:urine creatinine ratio.

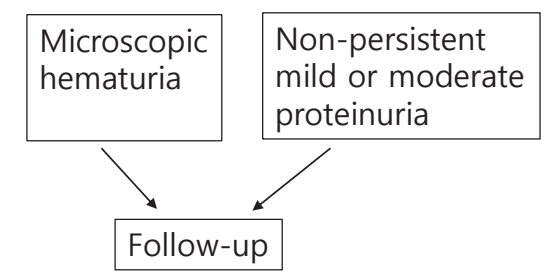

$(100<\mathrm{PCR}<250 \mathrm{mg} / \mathrm{mmol}),<50 \%$ crescents on biopsy, renal dysfunction, usually International Study of Kidney Disease in Children histological class IIIb. AZA, MMF, or intravenous CYC may also be added to the first- or second-line regimen. Cyclosporin or oral CYC cannot be routinely recommended for moderate IgAVN. A renal biopsy is necessary in patients with IgAV showing severe proteinuria (>250 $\mathrm{mg} / \mathrm{mmol}$ for at least 4 weeks, although a shorter duration of severe proteinuria also serves as a relative indication for biopsy) in those with persistent moderate (100 $\mathrm{mg} / \mathrm{mmol}$ ) proteinuria or impaired glomerular filtration rate). The treatment protocol for severe IgAVN (defined as $>50 \%$ crescents on renal biopsy and renal dysfunction,

Table 4. SHARE Recommendations for the Diagnostic Work-up of Immunoglobulin A Vaculitis Nephritis

\begin{tabular}{|c|c|}
\hline Number & Recommendations: Diagnosis \\
\hline \multicolumn{2}{|c|}{ Renal work-up } \\
\hline 1. & $\begin{array}{l}\text { Renal involvement should be investigated using eGFR } \\
\text { and urinalysis (haematuria and UP:UC ratio or UA:UC ratio) }\end{array}$ \\
\hline 2. & $\begin{array}{l}\text { A paediatric nephrologist should be consulted if an IgAV } \\
\text { patient has moderate proteinuria* and/or impaired GFR }\end{array}$ \\
\hline 3. & $\begin{array}{l}\text { A renal biopsy should be performed if an IgAV patient } \\
\text { has severe proteinuria ( }>250 \mathrm{mg} / \mathrm{mmol} \text { for at least } 4 \\
\text { weeks; although shorter duration of severe proteinuria is } \\
\text { also a relative indication for biopsy), persistent moderate } \\
\left(100-250 \mathrm{mg} / \mathrm{mmol}^{\prime}\right) \text { proteinuria }{ }^{\mp} \text { or impaired GFR }{ }^{\dagger}\end{array}$ \\
\hline
\end{tabular}

*Moderate proteinuria: UP:UC ratio $100-250 \mathrm{mg} / \mathrm{mmol}$ in an early morning urine sample.

${ }^{\dagger}$ Impaired GFR: $<80 \mathrm{ml} / \mathrm{min} / 1.73 \mathrm{~m}^{2}$.

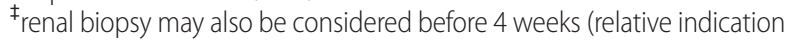
for biopsy), and persistence $>4$ weeks at this level is regarded as an absolute indication for renal biopsy.

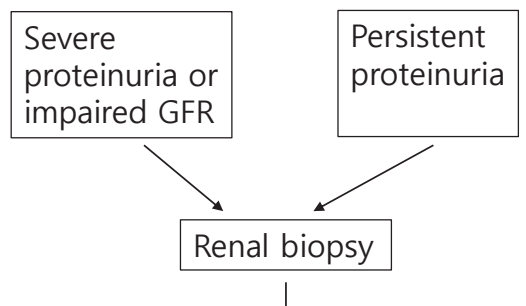

\begin{tabular}{|l|l|l|}
\hline Mild nephritis & Moderate nephritis & Severe nephritis \\
\hline $\begin{array}{l}1^{\text {st }} \text { line: } \\
\text { oral CS }\end{array}$ & $\begin{array}{l}1^{\text {st }} \text { line: } \\
\text { oral CS } \\
\text { and/or pulsed MP }\end{array}$ & $\begin{array}{l}1^{\text {st }} \text { line: } \\
\text { IV CYC with pulsed MP } \\
\text { and oral CS }\end{array}$ \\
\hline $\begin{array}{l}2^{\text {nd }} \text { line: } \\
\text { AZA. MMF, pulsed MP }\end{array}$ & $\begin{array}{l}1^{\text {st }} \text { or 2nd line: } \\
\text { AZA, MMF, IV CYC }\end{array}$ & $\begin{array}{l}2^{\text {nd }} \text { line: } \\
\text { AZA/MMF }+ \text { oral CS }\end{array}$ \\
\hline ACEi & \multicolumn{2}{|l}{} \\
\hline
\end{tabular}

Fig. 1 SHARE guidelines for the management of IgA vasculitis nephritis. ACEi, angiotensin converting enzyme inhibitor; IV, intravenous; MP, methylprednisolone; CYC, cyclophosphamide. 
ISKDC histopathological class IV-V disease, or nephrotic syndrome) is similar to that used for systemic small-vessel vasculitis with kidney involvement, e.g., antineutrophil cytoplasmic antibody-associated vasculitis. Treatment usually includes intravenous CYC with pulsed MP and/or oral prednisolone to induce remission, and lower doses of CS combined with AZA or MMF are administered as maintenance treatment.

\section{Other recommendations for the management of} immunoglobulin A vasculitis nephritis

Niaudet et al. ${ }^{55)}$ described the following therapeutic strategy for IgAVN in children: The authors are of the opinion that delaying the administration of potentially effective agents such as MP predisposes patients to chronic renal disease. On the other hand, patients with mild symptoms (i.e., microscopic hematuria, short-term macroscopic hematuria, or proteinuria $<1 \mathrm{~g} /$ day) do not require specific therapy. Urinary protein excretion and serum creatinine is measured once per week for one month and every 2 weeks for 2 months thereafter to monitor disease progression. Children with more severe renal involvement (i.e., proteinuria $>1$ g/day, nephrotic syndrome, or crescentic glomerulonephritis on renal biopsy) are administered three doses of intravenous MP at a dose of $1 \mathrm{~g} / 1.73 \mathrm{~m}^{2}$ (one dose daily, or on alternate days, for a total of three doses), followed by oral prednisone $30 \mathrm{mg} / \mathrm{m}^{2}$ once daily for one month and oral prednisone $30 \mathrm{mg} / \mathrm{m}^{2}$ every other day for 2 months.

\section{Other treatment}

1) Targeted-release budesonide formulation

Mucosal B lymphocytes located in Peyer's patches produce galactose deficient IgA1 (Gd-IgA1), which bind antiglycan IgG antibodies to form circulating immune complexes ${ }^{56)}$. A recent genome-wide association study involving patients with IgAN identified susceptibility gene loci that are associated with intestinal mucosal immunity ${ }^{57)}$. This pathogenesis suggests that local immunosuppression of mucosal B-lymphocyte activation and proliferation in Peyer's patches could attenuate Gd-IgA1 production. Targeted budesonide delivery to the distal ileum reduced proteinuria in patients with IgAN after 9-month treatment; a confirmatory phase 3 trial is currently underway ${ }^{58,59)}$.

More recently, Suzuki et $\mathrm{al}^{60)}$. reported that renal biopsy specimens stained using a monoclonal antibody to GdIgA1 (KM55) showed positive results in patients with primary IgAN or IgAVN; however, tissues obtained from patients with hepatitis $\mathrm{C}$ virus (HCV) nephritis with IgA deposits did not show such positive staining. Overall, these findings suggest that the pathogenesis of HCV-nephritis with IgA deposits that is typically observed in some patients with IgAN differs from that observed in patients with primary IgAN; therefore, targeted budesonide administration produced the same results in those with IgAVN but not in those with secondary IgAN.

\section{2) Eculizumab}

Mesangial immune complex deposition triggers a series of downstream pathways, including complement activation via the mannose-binding lectin and other pathways, precipitating glomerular injury and tubulointerstitial scarring. Plasma C3a levels were significantly elevated in 35\% of 46 adults with IgAN or IgAVN ${ }^{61-63)}$.

In this study, the plasma C3a level was significantly associated with serum creatinine concentrations but not with 24-hour urinary protein excretion.

Eculizumab, a humanized anti-C5 monoclonal antibody, has shown antiproteinuric effects in four patients with crescentic IgAN, and a phase 3 trial is currently underway ${ }^{57)}$.

3) Narsoplimab, a mannan-binding lectin-associated serine protease- 2 complement inhibitor

Phase 3 trials are underway to study the renal indications for administration of the anti-mannan-binding lectin-associated serine protease (MASP)-2 monoclonal antibody (OMS721), which blocks the lectin pathway, and MASP-2 has received orphan drug designation for atypical hemolytic uremic syndrome and $\operatorname{IgAN}{ }^{64)}$.

Mannan-binding lectin accumulates in the glomeruli in some patients and along with $\mathrm{C} 4 \mathrm{~d}$ deposition contributes to poor outcomes ${ }^{65)}$. These data and the increasing understanding that clinical inhibition of the lectin pathway might show therapeutic benefit in these patients, suggest that the lectin pathway plays a key role in the pathogenesis of this condition.

4) Rituximab

Reportedly, rituximab (an anti-CD20 chimeric mono- 
clonal antibody) has shown good effectiveness in a small study that included 8 patients with IgAVN, although a large study of patients with IgAN reported that rituximab did not significantly reduce serum levels of Gd-IgA1 or its antibodies $^{66,67)}$.

\section{5) Heparin}

Coagulation abnormalities have been implicated in the pathophysiology of IgAVN. After review of the available literature, the KDIGO group reported the results of a study, which showed that aspirin and dipyridamole were ineffective in preventing persistent kidney disease; ${ }^{27)}$ however, another study has suggested that low-molecular-weight heparin injections administered over 8 weeks were associated with a lower risk of ESKD and improved proteinuria ${ }^{68}$.

\section{6) Plasmapheresis}

Plasma exchange effectively removes circulating immune complexes during the acute phase of IgAVN. A study that investigated children with acute renal impairment, heavy proteinuria or both with histopathologically proven > grade 3 disease reported using early plasmapheresis alone in these patients. All children received at least nine exchanges with $70 \mathrm{~mL} / \mathrm{kg}$ for $4.5 \%$ human albumin solution per session during the first 2 weeks and the last $20 \mathrm{~mL} / \mathrm{kg}$ for fresh frozen plasma; 15 of the 16 children included in the study showed improvement after this therapy ${ }^{37)}$.

\section{7) Targeting the angiotensin system}

ACEi/ARB administration is recommended for the mild to severe proteinuria in patients with IgAN/IgAVN. Usually, the antiproteinuric effect of ACEi/ARB is attributable to their primary action on the intrinsic glomerular membrane where they enhance the barrier size-selective function in addition to efferent (postglomerular) arteriolar vasodilatation ${ }^{69,70)}$.

ACEi/ARBs inhibit mesangial cell (MC) stimulation that occurs after binding of angiotensin to specific $\mathrm{MC}$ receptors in patients with IgAN/IgAVN. Based on their mechanism of action, these drugs reduce proteinuria, $\mathrm{MC}$ proliferation, and renal fibrosis; however, endocapillary inflammation and crescent deposition are unaffected ${ }^{71,72)}$.

\section{8) Antileukotriene agents}

Montelukast (a leukotriene receptor antagonist) possesses potential anti-inflammatory properties, modulating the production of IL- 6 , tumor necrosis factor $\alpha$ (TNF- $\alpha$ ), and monocyte chemotactic protein. Studies have reported that montelukast reduced systemic symptoms including purpura, abdominal pain, arthritis, proteinuria and hematuria in patients with IgAVN and also inhibited relapses during the first 3 months after treatment. However, this drug did not affect the outcome of nephritis at the end of follow-up ${ }^{73-75)}$.

\section{9) Gluten-free diet}

The mean serum GD-IgA1 level was significantly higher in systemic IgAV than in cutaneous IgAV. High GD-IgA1 levels may predict systemic IgAV ${ }^{75)}$. Serum levels of GdIgA1-sCD89 complexes in patients with IgAN were associated with disease severity and progression but not with disease susceptibility ${ }^{1,76}$. Additionally, food components may contribute to the pathogenesis of IgAN. Gliadin (a component of gluten) is known to directly interact with sCD89, promoting IgAN development in a mouse model of $\operatorname{IgAN}{ }^{77)}$. Therefore, it is reasonable to conclude that a gluten-free diet may benefit patients with IgAVN as well ${ }^{78)}$.

\section{0) Infection eradication}

The onset of vasculitis is commonly preceded by an upper respiratory tract infection, which supports the role of a potential microbial etiopathogenesis in these patients. It is hypothesized that the antigenic structure of microorganisms resembles that of vessel walls in humans. Infection with these microorganisms could result in the production of cross-reactive anti-endothelial cell antibodies (AECA) known to be associated with vasculitis ${ }^{79)}$. Interestingly, IgA AECA isolated from patients with IgAVN are known to bind to bovine glomerular endothelial cells, whereas serum from patients with IgAV did not show such binding ${ }^{80)}$ suggesting that antigen-specificity of AECA differs between patients with $\operatorname{Ig} A V$ and $\operatorname{Ig} A \mathrm{NN}^{81)}$. In 40 children with IgAV (6.7 \pm 2.5 years), apical periodontitis, rhinosinusitis, and otitis media were identified in $53 \%, 48 \%$, and $10 \%$ of the children, whereas among 11 children with IgAN $(10.4 \pm 2.5$ years), these diseases were observed $55 \%, 18 \%$, and $0 \%$, respectively. Administration of antibiotics and root canal 
therapy resulted in complete cure without onset of nephritis or recurrent attacks in 31 of 40 children with IgAV whereas in all of the IgAN patients with various histological grades achieved normalization of urinalysis by $7.2 \pm 5.7$ months after the start of steroid therapy, not by eradication of infectious foci ${ }^{82)}$.

\section{1) Long non-coding RNA}

Reportedly, lncRNAs could be potential biological markers for IgAVN and are being viewed as possible pathogenetic contributors to glomerular and tubular injury and interstitial nephropathy, suggesting that lncRNA could be useful future therapeutic targets in these cases ${ }^{43)}$.

\section{Conclusions}

A shared pathophysiological mechanism may underlie the presentation of IgAN and IgAVN. The 2012 KDIGO guidelines recommend that patients with IgAVN with severe proteinuria should receive the same treatment as that used for patients with IgAN. The progress of the disease differs between children and adults. Following the KDIGO recommendation in 2012, the 2019 SHARE group established guidelines for the treatment of IgAVN in children. A prominent difference between the recommendations of these bodies is that the 2019 SHARE group recommends steroid use even in cases of mild proteinuria, although the portion for immunosuppressants is similar. Future research on the pathophysiology of IgAN and clinical trials that are currently underway are expected to result in the development of novel drugs in patients with IgAVN.

\section{ORCID}

Mee Kyung Namgoong https://orcid.org/0000-00028156-8970.

\section{Conflicts of interest}

No potential conflict of interest relevant to this article was reported.

\section{References}

1. Pillebout $E$, Jamin A, Ayari $H$, Housset P, Pierre M, Sauvaget $V$, et al. Biomarkers of IgA vasculitis nephritis in children. PLoS One 2017;12:e0188718.

2. Jennette JC, Falk RJ, Bacon PA, Basu N, Cid MC, Ferrario F, et al. 2012 Revised International Chapel Hill consensus conference nomenclature of Vasculitis. Arthritis Rheum 2013;65:1-11.

3. Mills JA, Michel BA, Bloch DA, Calabrese LH, Hunder GG, Arend WP, et al. The American College of Rheumatology 1990 criteria for the classification of vasculitis. Arthritis Rheum 1990;33:111421.

4. Ozen S1, Pistorio A, lusan SM, Bakkaloglu A, Herlin T, Brik R, et al. Paediatric Rheumatology International Trials Organisation (PRINTO). EULAR/PRINTO/PRES criteria for Henoch-Schönlein purpura, childhood polyarteritis nodosa, childhood Wegener granulomatosis and childhood Takayasu arteritis: Ankara 2008. Part Il: Final classification criteria. Ann Rheum Dis 2010;69:798806.

5. Jung DY, Kwon YR, Yu MH, Namgoong MK. Cinical Features and Prognosis of Henoch-Schönlein Purpura in Children and Adults: A 13-Year Retrospective Study at a Single Centre. Child Kidney Dis 2017;21:61-8.

6. Jauhola O, Ronkainen J, Koskimies O, Ala-Houhala M, Arikoski P, Hölttä T, et al. Renal manifestations of Henoch-Schönlein purpura in a 6-month prospective study of 223 children. Arch Dis Child 2010;95:877-82.

7. Saulsbury FT. Henoch-Schonlein purpura in children. Report of 100 patients and review of the literature. Medicine(Baltimore) 1999;78:395-409.

8. Calviño MC, Llorca J, García-Porrúa C, Fernández-Iglesias 」L, Rodriguez-Ledo P, González-Gay MA. Henoch-Schönlein purpura in children from northwestern Spain: a 20-year epidemiologic and clinical study. Medicine (Baltimore). 2001;80:279-90.

9. Narchi H. Risk of long term renal impairment and duration of follow up recommended for Henoch-Schönlein purpura with normal or minimal urinary findings: a systematic review. Arch Dis Child 2005;90:16-20.

10. Wang H, Das L Hoh SF, Gao X, Book YX, Arkachaisri T. Urinalysis Monitoring In Children With Henoch-Schönlein Purpura: Is It Time To Revise? Int J Rheum Dis 2019;22:1271-7.

11. de Almeida JL, Campos LM, Paim LB, Leone C, Koch VH, Silva CA. Renal involvement in Henoch-Schönlein purpura: a multivariate analysis of initial prognostic factors. J Pediatr 2007;83:259-66.

12. Alfredo CS, Nunes NA, Len CA, Barbosa CM, Terreri MT, Hilário MO. Henoch-Schönlein purpura: recurrence and chronicity. J Pediatr 2007;83:177-80.

13. Allen AC, Willis FR, Beattie TJ, Feehally J. Abnormal IgA glycosylation in Henoch-Schönlein purpura restricted to patients with clinical nephritis. Nephrol Dial Transplant 1998;13:930-4.

14. Ju T, Cummings RD. A unique molecular chaperone Cosmc required for activity of the mammalian core 1 beta 3-galactosyl- 
transferase. Proc Natl Acad Sci USA 2002;99:16613-8

15. He X, Zhao P, Kang S, Ding Y, Luan J, Liu Z, et al. C1GALT1 polymorphisms are associated with Henoch-Schönlein purpura nephritis. Pediatr Nephrol 2012;27:1505-9.

16. Mahajan V, Singh S, Khullar M, Minz RW. Serum and urine nitric oxide levels in children with Henoch-Schonlein purpura during activity and remission: a study from North India. Rheumatol Int 2009;29:1069-72.

17. Jiang J, Duan W, Shang X, Wang H, Gao Y, Tian P, et al. Inducible nitric oxide synthase gene polymorphisms are associated with a risk of nephritis in Henoch-Schönlein purpura children. Eur J Pediatr 2017;176:1035-45.

18. Ozkaya O. Söylemezoğlu O. Gönen S. Misirlioğlu M. Tuncer S. Kalman S, et al. Renin-angiotensin system gene polymorphisms: association with susceptibility to Henoch-Schonlein purpura and renal involvemene. Clin Rheumatol 2006;25:861-5.

19. Amoli MM, Thomson W, Hajeer AH, Calviño MC, Garcia-Porrua C, Ollier WE, et al. Interleukin 8 gene polymorphism is associated with increased risk of nephritis in cutaneous vasculitis. J Rheumatol 2002;29:2367-70.

20. Nathwani D, Laing RB, Smith CC, Edward N. Recurrent post-infective Henoch-Schonlein syndrome: a genetic influence related to HLA B35? J Infect 1992;25:205-10.

21. Amoli MM, Thomson W, Hajeer AH, Calviño MC, Garcia-Porrua C, Ollier WE, et al. HLA-B35 association with nephritis in HenochSchönlein purpura. J Rheumatol 2002;29:948-9.

22. Zhou TB, Ou C, Qin YH, Luo W. A meta-analysis of the association between angiotensin-converting enzyme insertion/deletion gene polymorphism and Henoch-Schönlein purpura nephritis risk in Asian children. Clin Exp Rheumatol 2012;30:315-6.

23. He X, Yin W, Ding Y, Cui SJ3, Luan J4, Zhao P1, et al. Higher serum angiotensinogen is an indicator of $\lg A$ vasculitis with nephritis revealed by comparative proteomes analysis. PLoS One 2015;10: e0130536.

24. Ronkainen J, Koskimies O, Ala-Houhala M, Antikainen M, Merenmies J, Rajantie J, et al. Early prednisone therapy in HenochSchönlein purpura: a randomized, double-blind, placebo-controlled trial. J Pediatr 2006;149:241-7.

25. Huber AM, King J, McLaine P, Klassen T, Pothos M. A randomized, placebo-controlled trial of prednisone in early Henoch Schönlein purpura. BMC Med 2004;2:7-13.

26. Dudley J, Smith G, Llewelyn-Edwards A, Bayliss K, Pike K, Tizard J. Randomized, double-blind, placebo-controlled trial to determine whether steroids reduce the incidence and severity of nephropathy in Henoch-Schonlein Purpura (HSP). Arch Dis Child 2013; 98:756-63.

27. Hahn D, Hodson EM, Willis NS, Craig JC. Interventions for preventing and treating kidney disease in Henoch-Schonlein Purpura (HSP). Cochrane Database Syst Rev 2015;7:Cd005128.

28. Coppo R, Mazzucco G, Cagnoli L, Lupo A, Schena FP. Long-term prognosis of Henoch-Scho"nlein nephritis in adults and children. Italian Group of Renal Immunopathology Collaborative Study on
Henoch-Schönlein purpura. Nephrol Dial Transplant 1997;12: 2277-83.

29. Goldstein AR, White RH, Akuse R, Chantler C. Long-term followup of childhood Henoch-Schönlein nephritis. Lancet 1992;339: 280-2.

30. Ronkainen J, Nuutinen M, Koskimies O. The adult kidney 24 yearsafter childhood Henoch-Schönlein purpura: a retrospective cohort study. Lancet 2002;360:666-70.

31. Butani L, Morgenstern BZ. Long-term outcome in children after Henoch-Schonlein purpura nephritis. Clin Pediatr (Phila) 2007;46: 505-11.

32. Fogazzi GB, Pasquali S, Moriggi M, Casanova S, Damilano I, Mihatsch MJ, et al. Long-term outcome of Schönlein-Henoch nephritis in the adult. Clin Nephrol 1989;31:60-6.

33. Huang X, Wu J, Wu XM, Hao YX, Zeng CH, Liu ZH, et al. Significance of histological crescent formation in patients with IgA vasculitis (Henoch-Schönlein purpura)-related nephritis: a cohort in the adult Chinese population. BMC Nephrol 2018;22:334-43.

34. Pillebout E, Thervet E, Hill G, Alberti C, Vanhille P, Nochy D. Henoch-Schönlein Purpura in adults: outcome and prognostic factors. J Am Soc Nephrol 2002;13:1271-8.

35. Niaudet P, Habib R. Methylprednisolone pulse therapy in the treatment of severe forms of Schönlein-Henoch purpura nephritis. Pediatr Nephrol 1998;12:238-43.

36. Hattori M, Ito K, Konomoto T, Kawaguchi H, Yoshioka T, Khono M: Plasmapheresis as the sole therapy for rapidly progressive Henoch-Scho"nlein purpura nephritis in children. Am J Kidney Dis 1993:33:427-33.

37. Shenoy M, Ognjanovic MV, Coulthard MG: Treating severe Henoch-Scho"nlein and lgA nephritis with plasmapheresis alone. Pediatr Nephrol 2007;22:1167-71.

38. Lan HY, Nikolic-Paterson DJ, Mu W, Vannice JL, Atkins RC: Interleukin-1 receptor antagonist halts the progression of established crescentic glomerulonephritis in the rat. Kidney Int 1995;47: 1303-9.

39. Khan SB, Cook HT, Bhangal G, Smith J, Tam FW, Pusey CD: Antibody blockade of TNF-alpha reduces inflammation and scarring in experimental crescentic glomerulonephritis. Kidney Int 2005; 67:1812-20.

40. López-Mejías R, Castañeda S, Genre F, Remuzgo-Martínez S, Carmona FD, Llorca J, et al. Genetics of immunoglobulin-A vasculitis (Henoch-Schönlein purpura): an updated review. Autoimmun Rev 2018;17:301-15.

41. Kung JT, Colognori D, Lee JT. Long noncoding RNAs: Past, present, and future. Genetics 2013;193:651-69.

42. Kapusta A, Feschotte C. Volatile evolution of long noncoding RNA repertoires: Mechanisms and biological implications. Trends Genet 2014;30:439-52.

43. Pang S, Lv J, Wang S, Yang G, Ding X, Zhang J. Differential expression of long non-coding RNA and mRNA in children with Henoch-Schönlein purpura nephritis. Exp Ther Med 2019;17:62132. 
44. Kidney Disease: Improving Global Outcomes. Chapter 11: Henoch-Schonlein purpura nephritis. Kidney Int Suppl(2011) 2012;2:218-20.

45. Emancipator SN (1993) Primary and secondary forms of IgA nephritis and Schönlein-Henoch syndrome. In: Heptinstall RH (ed) Pathology of the kidney. Little Brown, London, pp 389-476.

46. Davin JC, Ten Berge IJ, Weening JJ. What is the difference between IgA nephropathy and Henoch-Schönlein purpura nephritis? Kidney Int 2001;59:823-4.

47. Andersen RF, Rubak S, Jespersen B, Rittig S. Early high-dose immunosuppression in Henoch-Schönlein nephrotic syndrome may improve outcome. Scand J Urol Nephrol 2009;43:409-15.

48. Davin JC, Coppo R. Pitfalls in recommending evidence-based guidelines for a protean disease like Henoch-Schönlein purpura nephritis. Pediatr Nephrol 2013;28:1897-903.

49. 2018 - KDIGO Clinical Practice Guideline for Glomerulonephritis. KDIGO GN Guideline update - Evidence summary. (https://kdigo. org/wp-content/uploads/2018/08/Chap-12-Lupus-nephritisevidence-summary_final_profiles.pdf).

50. Tarshish P, Bernstein J, Edelmann CM Jr. Henoch-Schönlein purpura nephritis: course of disease and efficacy of cyclophosphamide. Pediatr Nephrol 2004;19:51-6.

51. Rauen T, Eitner F, Fitzner C, Sommerer C, Zeier M, Otte B, et al. STOP-IgAN Investigators. Intensive Supportive Care plus Immunosuppression in IgA Nephropathy. N Engl J Med 2015;373:222536.

52. Lv J, Zhang H, Wong MG, Jardine MJ, Hladunewich M, Jha V, et al. Effect of oral methylprednisolone on clinical outcomes in patients with IgA nephropathy: the TESTING randomized clinical trial. JAMA 2017;318:432-42.

53. Management and treatment of glomerular diseases (part 1): conclusions from a Kidney Disease: Improving Global Outcomes (KDIGO) Controversies Conference. Kid Int 2019;95:268-80.

54. Ozen S, Marks SD, Brogan P, Groot N, de Graeff N, Avcin T, et al. European consensus-based recommendations for diagnosis and treatment of immunoglobulin A vasculitis-the SHARE initiative. Rheumatology 2019;58:1607-16

55. Niaudet P, Appel GB, Hunder GG. IgA vasculitis (Henoch-Schönlein purpura): Renal manifestations [Internet]. UpToDate:[cited 2019 Sep 10]. Available from: https://www.uptodate.com/contents/ iga-vasculitis-henoch-schonlein-purpura-renal-manifestations.

56. Smith AC, Molyneux K, Feehally J, Barratt J. O-glycosylation of serum IgA1 antibodies against mucosal and systemic antigens in IgA nephropathy. J Am Soc Nephrol 2006;17:3520-8.

57. Gharavi AG, Kiryluk K, Choi M, Li Y, Hou P, Xie J, et al. Genomewide association study identifies susceptibility loci for IgA nephropathy. Nat Genet 2011;43: 321-7.

58. Block GA, Whitaker S. Maintenance of remission following completion of OMS721 treatment in patients with IgA nephropathy (IGAN). Abstract SA-P0278. J Am Soc Nephrol 2017;28:749-50.

59. Fellström BC, Barratt J, Cook H, Coppo R, Feehally J, de Fijter JW, et al. Targeted-release budesonide versus placebo in patients with IgA nephropathy(NEFIGAN): a double-blind, randomised, placebo-controlled phase 2b trial. Lancet 2017;389:2117-27.

60. Suzuki H, Yasutake J, Makita Y, Tanbo Y, Yamasaki K, Sofue T, et al. IgA nephropathy and IgA vasculitis with nephritis have a shared feature involving galactose-deficient IgA1-oriented pathogenesis. Kidney Int 2018;93:700-5.

61. Maillard N, Wyatt RJ, Julian BA, Kiryluk K, Gharavi A, FremeauxBacchi $V$, et al. Current understanding of the role of complement in IgA nephropathy. J Am Soc Nephrol 2015;26:1503-12.

62. Hisano S, Matsushita M, Fujita T, Iwasaki H: Activation of the lectin complement pathway in Henoch-Schonlein purpura nephritis. Am J Kidney Dis 2005:45:295-302.

63. Abou-Ragheb HH, Williams AJ, Brown CB, Milford-Ward A. Plasma levels of the anaphylatoxins C $3 a$ and C4a in patients with IgA nephropathy/Henoch-Schonlein nephritis. Nephron 1992;62: 22-6.

64. Omeros. FDA grants orphan drug designation to Omeros' OMS721 for treatment of IgA nephropathy. Omeros. 2017 http://investor. omeros.com/phoenix.zhtml?c=219263\&p=irol-newsArticle_ Print $\& \mid D=2292002$.

65. Espinosa M, Ortega R, Sánchez M, Segarra A, Salcedo MT, González $\mathrm{F}$, et al. Association of C4d deposition with clinical outcomes in IgA nephropathy. Clin J Am Soc Nephrol 2014;9:897-904.

66. Crayne CB, Eloseily E, Mannion ML, AzerfSP, Weiser P, Beukelman $T$, et al. Rituximab treatment for chronic steroid-dependent Henoch-Schonlein purpura: 8 cases and a review of the literature. Pediatr Rheumatol Online J 2018;16:71.

67. Lafayette RA, Canetta PA, Rovin BH, Appel GB, Novak J, Nath KA, et al. A Randomized, Controlled Trial of Rituximab in IgA Nephropathy with Proteinuria and Renal Dysfunction. J Am Soc Nephrol 2017;28:1306-13.

68. Tian M, Liu C. Heparin calcium treated Henoch-Schonlein purpura nephritis in children through inhibiting hyperfibrinolysis. Ren Fail 2015;37:1100-4.

69. Heeg JE, de Jong PE, van der Hem GK, de Zeeuw D. Reduction of proteinuria by angiotensin converting enzyme inhibition. Kidney Int 1987;32:78-83.

70. Remuzzi A, Perticucci E, Ruggenenti P, Mosconi L, Limonta M, Remuzzi G. Angiotensin converting enzyme inhibition improves glomerular size-selectivity in IgA nephropathy. Kidney Int 1991; 39:1267-73.

71. Ninchoji T, Kaito H, Nozu K, Hashimura Y, Kanda K, Kamioka I, et al. Treatment strategies for Henoch-Schönlein purpura nephritis by histological and clinical severity. Pediatr Nephrol 2011;26:5639.

72. Coppo R, Peruzzi L, Amore A, Piccoli A, Cochat P, Stone R, et al. Igace: a placebo-controlled, randomized trial of angiotensinconverting enzyme inhibitors in children and young people with IgA nephropathy and moderate proteinuria. J Am Soc Nephrol 2007;18:1880-8.

73. Maeba S, Ichiyama T, Ueno Y, Makata H, Matsubara T, Furukawa 
S. Effect of montelukast on nuclear factor kappaB activation and proinflammatory molecules. Ann Allergy Asthma Immunol 2005;94:670-4.

74. Wu SH, Liao PY, Chen XQ, Yin PL, Dong L. Add-on therapy with montelukast in the treatment of Henoch-Schönlein purpura. Pediatr Int 2014;56:315-22.

75. Neufeld M, Molyneux K, Pappelbaum Kl, Mayer-Hain S, von Hodenberg C, Ehrchen J, et al. Galactose deficient IgA1 (GD-lgA1) in skin and serum from patients with skin-limited and systemic IgA Vasculitis. J Am Acad Dermatol 2019;19:30443-8.

76. Vuong MT, Hahn-Zoric M, Lundberg S, Gunnarsson I, van Kooten C, Wramner L, et al. Association of soluble CD89 levels with disease progression but not susceptibility in IgA nephropathy. Kidney Int 2010;78:1281-7.

77. Papista C, Lechner S, Ben Mkaddem S, LeStang MB, Abbad L, Bex-Coudrat J, et al. Gluten exacerbates IgA nephropathy in humanized mice through gliadin-CD89 interaction. Kidney Int 2015;88:276-85.
78. Landecho MF, Ros NF, Alegre F, Idoate MA, Lucena JF. HenochSchönlein purpura associated with celiac disease. J Am Acad Dermatol 2011;64:e120-1.

79. Legendre P, Régent A, Thiebault M, Mouthon L. Anti-endothelial cell antibodies in vasculitis: a systematic review. Autoimmun Rev 2017;16:146-53.

80. Fujieda M, Oishi N, Naruse K, Hashizume M, Nishiya K, Kurashige T, et al. Soluble thrombomodulin and antibodies to bovine glomerular endothelial cells in patients with Henoch-Schonlein purpura. Arch Dis Child 1998;78:240-4.

81. Yang YH, Wang SJ, Chuang YH, Lin YT, Chiang BL. The level of IgA antibodies to human umbilical vein endothelial cells can be enhanced by TNF-a treatment in children with Henoch-Schönlein purpura. Clin Exp Immunol 2002;130:352-7.

82. Inoue CN, Matsutani S, Ishidoya M, Homma R, Chiba Y, Nagasaka T. Periodontal and ENT therapy in the treatment of pediatric henoch-schönlein purpura and IgA nephropathy. Adv Otorhinolaryngol 2011;72:53-6. 